\title{
El último patriarca, de Najat EL Hachmi: Una lectura sociolinguiística'
}

\author{
Najat EL Hachmi’s El último patriarca, a Sociolinguistic Reading
}

\author{
ANTONIO DANIEL FUENTES GONZÁLEZ \\ Universidad de Almería \\ España \\ dfuentes@ual.es
}

(Recibido 29-IO-2OI2; aceptado IO-O2-2OI3)

Resumen. Llama la atención que la sociolingüística se haya acercado con poca intensidad a la literatura, a pesar de que esta se constituye como un entramado discursivo notoriamente social, especialmente por su ambición de verosimilitud. Partiendo de esta premisa, se propone una lectura sociolingüística de El último patriarca, conectando los hitos sociolingüísticos de los personajes con su lucha social. Manel-Mimoun procurará ser un patriarca implacable y su hija una mujer libre que conquista una nueva identidad. En este recorrido lector se activa un turismo lingüístico-literario, de visita a un paisaje emocional que frecuentemente será recalar en rincones intencionadamente olvidados de nuestra geografía histórico-sentimental.

Palabras clave: Sociolingüística; plurilingüismo; lectura; migraciones; interculturalidad.

Abstract. It is a surprising fact that Sociolinguistics has approached the realm of Literature with low intensity. It particularly draws the attention because it is a notoriously social discourse frame and even more if we regard for this discipline ambition for verisimilitude. Starting from this ground, the author of this study proposes a sociolinguistic reading of El último patriarca by connecting the characters' sociolinguistic landmarks with their social fight. The character Manel-Mimoun will try to become an implacable patriarch and his daughter will attempt to be a free woman that conquers a new identity. Through this reading journey a kind of linguistic and literary tourism is triggered. It is like visiting an emotional landscape that frequently will consist of visiting hidden corners of our sentimental and historical geography, spaces that are forgotten on purpose.

Keywords: Sociolinguistics; Multilinguialism; Reading; Migrations; Interculturalism.

Zusammenfassung. Die Soziolinguistik hat sich mit weniger Intensität an die Literatur angenähert, obwohl sie sich durch einen sozialen Diskurs, vor allem durch ihre Wahrscheinlichkeit charakterisiert. Ausgehend von dieser Bedingung, stellt man eine soziolinguistische Lektüre El último patriarca vor, in dem man die soziolinguistischen Meilensteine der Personen mit ihrem sozialen Kampf verbindet. Manel-Mimoun versucht ein totales Patriach zu sein. Seine Tochter, eine emanzipierte Frau, die sich eine neue Identität verordnet. In dieser Lektüre wird ein linguistisch-literarischer Turismus aktiviert. Das kann einen Besuch in unsere emotionale Landschaft, die wir häufig bewusst vergessen, bedeuten.

Schlüsselwörter: Soziolinguistik; Mehrsprachigkeit; Lektüre; Migrationen; Interkulturalität.

\footnotetext{
${ }^{\text {I }}$ Para citar este artículo: Fuentes González, A. Daniel (20I3). El último patriarca, de Najat EL Hachmi: Una lectura sociolingüística. Alabe 8. [www.revistaalabe.com]
} 


\section{I - Introducción}

La escritora catalana Najat El Hachmi (Nador, Marruecos, I979) publica L'últim patriarca en 2008, casi al mismo tiempo que su versión en castellano El último patriar$c a^{2}$, ambas en la editorial Planeta. Pocos años antes, su aparición en las letras catalanas se producía con la publicación del ensayo Jo també sóc catalana (Barcelona, Ed. Columna, 2004) como una reivindicación de su comunidad de procedencia, al tiempo que un signo de la potente apertura sociocultural de Cataluña.

La novela cuenta la historia de Mimoun Driouch y de su familia desde el punto de vista de su hija, una niña sin nombre. Mimoun emigra desde el Rif (Norte de Marruecos) hasta la ciudad catalana de Vic, primero solo y reagrupado después con su familia. La niña se irá convirtiendo en una mujer que lucha por ser ella misma en medio de las tensiones del poder familiar rifeño y de la sociedad catalana, al menos aparentemente. Puede que su interés literario esté en que la historia transcurre entre ambos polos vivenciales, confrontados críticamente, sin asentarse totalmente en ninguno. De hecho, Ricci (2OIO: 6) apunta que en EUP “las categorías taxonómicas se hacen trizas una por una para dejar en claro que no se trata de novelar meramente sobre las diferencias entre África y Europa, hombre y mujer", superación de lo que Grimson (2008: 53) considera una uniformidad imaginada en muchas descripciones culturales, basadas en identidades estáticas, que suelen pasar por alto tanto diferencias internas de los Otros, como también heterogeneidades del Nosotros ${ }^{3}$.

Sobre la emigración desde el Rif, la bibliografía ha señalado también el proceso de pérdida de autoridad patriarcal en beneficio del diálogo y de la convivencia (Eguren Rodríguez (2003: 7). Del mismo modo, EUP ha quedado adscrita al género de la novela de inmigración, también de exilio. Por lo pronto parece quedar encajada en esta categoría, probablemente por la percepción de la diferencia desde esa atalaya monolítica identitaria de la llamada sociedad de acogida. Dado que esa navegación cultural entre dos aguas es un topos muy presente en la novela, conectaré su lectura con los procesos de encuentro o de integración sociolingüísticos y sus diferentes circunstancias, precisamente porque la desigualdad social causante de una inmigración forzada se instala en otro destino de desigualdad, rota parcialmente en la novela por la igualdad en el uso de la lengua, en este caso de la lengua catalana en la versión original, y de su traducción al castellanó4.

\footnotetext{
${ }^{2}$ En adelante $E U P$.

3 Así, en Fuentes González (2OI3) analizo la significación discursiva y sociolingüística de los gentilicios en esta misma obra de El-Hachmi.

4 Ricci (20IO: I9) considera que en el proceso de traducción del catalán al castellano el texto pierde mucho de la plasticidad lingüística del original (concisión, exactitud y fuerza expresiva).
} 
Al hilo de esta conexión, puede parecer sorprendente que la sociolingüística no se haya prodigado tanto en escrutar los procesos sociolingüísticos de una creación literaria. Sin embargo, se ha insistido en el carácter social de la literatura y en su potencial crítico (Fowler I988), tanto que en el lamento por ese alejamiento disciplinar, Lambert, Meylaerts y Borden (2005:II) denuncian que la sociolingüística no haya sido tenida en cuenta por parte de los especialistas de las literaturas.

\section{2 - Aspectos metodológicos}

Si EUPes considerada una novela de inmigración/exilio, la autora ha pulsado bien los hitos sociolingüísticos de los personajes principales. Consiguientemente, no extraña que haya referencias a los estados inestables de la interlengua de Mimoun, adulto llegado del Rif, cargado con su equipaje de percepciones y valoraciones sociolingüísticas, pero también de menciones importantes a la mediación intercultural cooperativa en la ruptura de los prejuicios, o del papel y estructura de las hablas extranjeras y/o para extranjeros, entre otros elementos narrativos que se observarán con más detalle. Tampoco extraña la importancia sociolingüística de un denso escenario plurilingüe, cuyos ingredientes principales son el catalán, el rifeño, el español y el árabe . La niña, por otro lado, llega a Vic con ocho años, de manera que su plurilingüismo se irá desarrollando mucho más hacia la catalanidad lingüística plena que hacia la expansión de un repertorio funcional en rifeño.

En este trabajo se pretende seguir abriendo una panorámica atenta hacia el papel que juegan en lo literario el reflejo y las posibilidades sociolingüísticas de determinadas realidades. La forma de presentar esta conexión constituye una parada importante en este planteamiento teórico. Solé i Camardons (2OOI: I4I-42) destaca con mucha honestidad que en sociolingüística el excesivo culto al método puede ser contraproducente, dada la versatilidad de su objeto de estudio. No existe una uniformidad teórica, ni tampoco una univocidad metodológica para abarcar la multidimensionalidad del hecho lingüístico y comunicativo, libertad que enlaza con la fidelidad a los valores de verosimilitud de toda obra literaria (Thon, I998). La literatura quedaría empíricamente definida dentro del campo sociolingüístico, en tanto que discurso social observable desde una perspectiva macro-sociolingüística, producto y expresión de hechos ampliamente basados en la organización social y económica de una comunidad (Thon, I998: 4-5).

Todo ello invita a usar instrumentos disciplinares de intersección metodológicamente plurales (Ballester e Ibarra, 2009); Martos y Campos (20I2). La lectura, cualquier lectura, puede enriquecer incesantemente los sentidos de la escritura. Fowler (I988: I36I46) ponía de manifiesto que la atención del lector es secuencial, sacudida por significaciones capaces de configurar un índice de los lugares textuales que han llamado la atención de varios lectores. Esos lugares textuales son dinámicos en el tiempo, al urdir una 
sintagmática de la lectura y al asentar una interacción discursiva entre los participantes del acto lector. Como se verá, este recorrido activa un turismo lingüístico-literario, de visita a un paisaje emocional que a veces será frecuentar también rincones intencionadamente olvidados de nuestra geografía histórico-sentimental.

La relación de topos textuales procede inicialmente de una lectura general, no profesional, más específica después, que invitaba a subrayar aquellos fragmentos indicativos de una dialéctica integradora sociolingüística en una comunidad de llegada. Me llamó también la atención la invisibilidad -muy bien lograda- de que estaba leyendo una traducción del catalán al español o castellano, aún cuando el modo de conocimiento que tuve de la obra hiciese muchísimo hincapié en la catalanidad de Najat El Hachmi. Esa invisibilidad traductora, lejos de ser extraña al circuito de los discursos migrantes, constituye un recurso de primer orden (Lambert, I999): la traducción, quienes traducen o interpretan deben desaparecer, precisamente porque parte de su función es ser imperceptibles. De ahí que ante el conjunto inicial de los temas más consagrados por la sociolingüística (García Marcos, I999), fuese apropiado indagar en el aspecto traductor de la obra ${ }^{6}$.

Posteriormente utilicé didácticamente los fragmentos seleccionados por su interés sociolingüístico. De ahí que el panorama lector de la novela EUP quede beneficado por observaciones etnolectales, con luchas genuinamente generacionales, necesitadas de mediaciones interlingüísticas e interculturales o, desde luego, con la salida a escena de una durísima emancipación femenina, donde todo se conquista, sin que haya concesiones tanto por el origen como por la adaptación a la comunidad de llegada.

En sintonía con la novedad literaria de EUP, Bueno Alonso (20Iо: II) resalta que "el texto se publicó simultáneamente en francés, castellano y catalán desde donde se vislumbra un cierto deseo de recepción del texto en el ámbito mediterráneo", tanto que "...la edición simultánea en tres lenguas convierten esta novela en un modelo perfecto-demasiado quizás- de un texto polifónico, símbolo del crisol cultural de la España actual." Frente a ese crisol, una cuestión que no debe olvidarse en comunicación intercultural es que no se juntan las lenguas, sino que lo hacen básicamente las personas, percibidas como miembros de un grupo.

\section{3 - Las tribulaciones sociolingüísticas de Mimoun, que será también Manel}

El patriarca Mimoun irá adquiriendo el nuevo idioma, espoleado por la necesidad de entender y de ser entendido en una comunidad en la que trabajará como albañil, al

\footnotetext{
${ }^{6}$ Lo que dejo para otro ensayo, primeramente desde una perspectiva general concretada en dos lenguas iberorrománicas, el catalán como lengua de origen y el español como lengua de llegada, si bien podría observarse una ampliación que tenga en cuenta la versión francesa, u otras que puedan publicarse.
} 
principio por cuenta ajena y luego por cuenta propia. Una operación cognitiva de frecuente uso en la comunicación en contacto cultural y lingüístico es la percepción selectiva o categórica. Se tiende a poner de relieve lo diferente, la disidencia respecto de la cultura propia, mediante usos lingüísticos, culinarios, horarios, rituales. Ese tipo de percepción parece primordial en los primeros momentos del contacto, tanto que alimenta preconceptos y estereotipos varios. Otras veces, cuando la coexistencia va cuajando, parece ganar más terreno la profundidad cognoscitiva. En nuestra literaratura se descubre la importancia de la oposición moro peninsular vs. moro africano (Querol Sanz, 2OIO). EUP es también una narración donde se reflejan cuestiones esencialistas, al señalar el estereotipo lingüístico que adjudica al español una dimensión imperativa, proveniente de su dureza. En EUP( $\left.{ }_{6} 6-77\right)$, evocando los preparativos de la planificación de la estancia inicial, a su padre la niña narradora

No se lo imaginaba con los españoles, aguantando todo lo que le dijeran, los insultos, como solían hacer con los moros. No se lo imaginaba sometido a un jefe español que le mandase todo el rato lo que tenía que hacer y cómo lo tenía que hacer, ni siquiera dos años.

Aparece la violencia del acomodo lingüístico, especialmente porque viene dado a partir de historias orales que estigmatizan el español como la lengua del amo, la lengua de la opresión, operativa como nunca en el esquema Los españoles insultan a los moros, seguramente como una táctica de bestialización del otro para poder soportar su sumisión infrahumana como bestias de trabajo humilladas:

Había quien hablaba como él, y a algunos pocos los entendía. Había quien hablaba español, y él solo conseguía recordar los insultos que su padre gritaba en esta lengua, aprendidos cuando trabajaba para ellos (EUP, 80).

Parece algo que sucede instintivamente; el desconocimiento queda vinculado al terror al insulto, a la exclusión. Lo hace de tal modo que -a menudo- en la adquisición lingüística hay preparativos especiales para anotar cuáles son los insultos más habituales, por si acaso. En realidad pareciera una estrategia de supervivencia, como si la nueva adquisición fuese una gran batalla.

Avanzado el proceso migratorio, esa posible vinculación de dimensiones apriorísticas queda disuelta por la fuerza individual. La condición de una persona convierte un acto verbal en insultante, y hay activadores discursivos, como uxtia puta (EUP, 287), que anuncian la tormenta, también en la la neolengua. Esa reciprocidad apriorística llega irracionalmente; el insulto apestosa cristiana de mierda $(E U P, 287)$ es bastante revelador. Si escribimos apestosa [cristiana] de mierda asociamos dos condiciones bastante denigratorias; al intercalar como sustantivo cristiana, el término queda apresado en una pinza sintagmática de la que no se puede escapar, de tal forma que fortalece una condición de convivencia cultural basada en una tolerancia en frágil equilibrio; si haces algo malo, el paradigma está en el Otro, en el mundo cristiano. Esta operación discursiva no es desde 
luego monopolio del grupo marroquí-bereber, pues se ha visto que tanto la usan como la padecen, garantizando un imaginario de profilaxis en lo propio y de falta de higiene en los demás. Tanto es así que, para el caso italiano, Olivieri (I999) documenta esas mismas estrategias para construir la imagen del otro como inintegrable, ya que la población italiana emigrada a la Argentina a finales del XIX y primeros años del siglo XX llegaba a ser categorizada como delincuentes (sucios), categoría que hoy la población italiana, y buena parte de la europea también, reserva para los inmigrantes llegados al Norte mediterráneo.

En la novela existen, por descontado, más referencias denotativas de esa interesada y cómoda uniformidad imaginaria:

Todavía era exótico ver a un moro en medio de una ciudad tan de interior y bastante a menudo había quien se volvía y se quedaba mirando con la mano tapándose la boca para no mostrar más de la cuenta la sorpresa. Sobre todo las señoras, que recordaban historias de magrebíes asesinos durante la guerra que habían cortado cabezas a todo aquel que se les ponía por delante y que las colgaban después por el pelo en medio de la plaza. $\mathrm{O}$ al menos eso era lo que se había oído decir (EUP, 88).

\section{Sin embargo, Manel}

no se dio demasiada cuenta de cómo sorprendía su presencia ni podía saber qué pensaban de él sus vecinos o sus compañeros de trabajo. No entendía su lengua y bastante tenía con aprender las cuatro frases rudimentarias que le servían para comprender las órdenes del jefe o para pedir algo de comer en el restaurante (EUP, 88-89).

Las cosas cambiarían, pues a partir de esas cuatro frases sencillas ampliaría el léxico, bromeando, comprendiendo muchos giros idiomáticos, franqueando la literalidad más referencial e intuyendo significados. Pero entretanto el futuro patriarca

Hasta que supo pedir otra cosa, se pasó semanas comiendo bocadillos de tortilla. Un bocadillo de tortilla, por favor. Su tío le decía que parecía una de esas serpientes que solo comen huevos de gallina y que nunca se hubiera imaginado que tuviera esa afición por los huevos (EUP, 89).

Con el tiempo, los nuevos retos laborales repercutirían notablemente en su fluidez discursiva:

La obra de la granja de cerdos del pueblo de al lado se había acabado y ya no trabajarían más allí. El jefe lo cargó a él solo hasta la cima de una montaña y le dijo: es aquí. Se pasaría seis meses viajando cada día para ir a acabar la casa del jefe con muchos otros albañiles que ya hacía tiempo que trabajaban allí. EI tío se fue a otra obra y Manel comenzó a soltarse con el nuevo idioma (EUP, 89).

Dentro de ese entorno de percepción selectiva se hace importante pasar desaper- 
cibido, no dar demasiado que hablar, rehaciendo unas costumbres alimenticias por buenas maneras y por talante práctico, sin que dejase de actuar una incipiente conciencia lingüística en la neolengua:

A mediodía les daban la comida en un restaurante de mesas de madera de las de verdad, barnizadas de marrón oscuro y con las huellas de los troncos aún marcadas. Se llamaba Cal Met, y Manel debía de intuir que eso no venía de Mohamed.

Mimoun se iba sintiendo más a gusto, ya entendía lo que le decían tanto los compañeros como todo el grupo del restaurante donde iban a comer. Se sentía especialmente acogido por Ramona, aquella mujer tan gorda que le llenaba una y otra vez el plato de macarrones con carne o butifarra con judías.

Eso no quería decir que ya no le preocupase el tipo de carne que comía, solo que en ocasiones llegaba tan hambriento del trabajo que ni tiempo tenía de fijarse en qué había y qué no dentro del plato. Por buena educación, tampoco se atrevía a preguntar qué era y aún menos habría rechazado un plato cocinado con tanta destreza por la señora de la casa (EUP, 89).

Todo ello recuerda numerosas experiencias de la emigración-inmigración: ¿en qué nivel lingüístico se autopercibe el migrante y en qué nivel lo perciben los demás? o ¿por qué muchos migrantes se anclan en un determinado dominio lingüístico? Puede ser que con el pidgin de esas cuatro frases, de carácter marcadamente informativo (Fuentes González, 2005 y $2005^{\text {a }}{ }^{7}$, como digo, no se pretenda comunicar, únicamente subsistir. El acomodo es cómodo; no tienes que hablar demasiado, es poco conflictivo y marca perfectamente dónde quiere estar cada uno, como si a mayor información, se tuviera menos necesidad de interpretación, evitando malentendidos.

La toma de confianza con el nuevo idioma parece correlativa de una nueva situación laboral: eres jefe, debes de hablar más; hay que poner de relieve que no es la lengua la que invoca al trabajo, sino el trabajo el factor que excita y concita el aprendizaje-adquisición lingüísticos, a pesar de que normalmente se nos quiera hacer creer lo contrario. Eres jefe, hablas más, por obligación. Por ello me ha sorprendido cómo las presuposiciones bienintencionadas que desde la comunidad docente tenemos (el español como factor de integración) quedan canceladas en algunas actividades laborales, en las que la capacidad verbal se interpreta como capacidad para protestar y como bajo rendimiento. Si hablas español, no te llaman, me decía en I999 un alumno marroquí en un curso de mediación intercultural. Como se dice en ciertos contextos laborales, que no te llamen a trabajar es también la vergonzosa recuperación de prácticas laborales que padecían abuelos españoles, cuando en la plaza del trabajo esperaban por la mañana a que el patrón les pulseara el brazo para llamarlos a ganar el jornal, para lo que es meritorio tener la boca cerrada, que no protesta y no se queja.

7 Precisamente la sociolingüística germánica (Löffler ı985) descubría la importancia de estos factores al estudiar la configuración sociolingüística del pidgin de los trabajadores extranjeros italianos y españoles en la R. F. de Alemania. 
De cualquier forma, las lenguas están mercantilizadas. Gutiérrez (2007) ha destacado la relación entre las características lingüísticas de los inmigrantes y sus logros en el mercado de trabajo. Si en el uso lingüístico asumimos las prototípicas relaciones de importación-exportación, Morelló (2002: 252) asegura que

Les persones immigrants han de poder tenir accés a l'aprenentatge del valencia com qualsevol altre ciutada o ciutadana. D'aquesta manera tindran les mateixes possibilitats d'arrelament, de desenvolupament de la personalitat i de pertinença a la col.lectivitat, i es podran desenvolupar socialment i professional.

Es decir, a mayor nivel de dominio, mayores oportunidades de mejorar el empleo. En ese entramado sociolingüístico las migraciones vienen propiciadas porque desde dos ámbitos comunitarios se favorece el viaje, porque hay posibilidades de empleo mejor pagado y necesidades de que esos empleos sean cubiertos, lo que -dicho sea de paso- ha concitado la atención por las certificaciones lingüísticas (Martín Leralta, 2OII; Baralo y Estaire, 2OII $)^{8}$. En cualquiera de los casos, la economía del mercado lingüístico queda asociada a otra buena serie de factores que pueden garantizar o no la (des)integración sociolingüística. La cotidianidad en el nuevo país puede verificar las expectativas que atribuyen un incremento salarial gracias al dominio idiomático, si la estancia se prolonga o si se prolonga indefinidamente, si hay matrimonio con alguien natural del nuevo país o con el país de procedencia, si se tienen niños o no, si hay agrupamiento vecinal de la comunidad de origen, si la ampliación comunicativa en la neolengua es consciente y se somete a un aprendizaje reglado, si se aprecia cercanía o distancia lingüística entre las lenguas en contacto o qué edad se tiene cuando se emigra y el nivel formativo previamente consegui$\mathrm{do}^{9}$.

En EUP se aprecia la posibilidad, por otra parte, de que la ampliación del repertorio funcional ensanche el potencial comunicativo, sobreponiéndose a actos meramente informativos; una vez asentado un hábito, es más difícil cambiarlo, como en la tolerancia alimenticia hacia las butifarras con judías. Igualmente puede apreciarse cómo actúa la cortesía lingüística, capaz de convertirse en un acto de sumisión (en la entrevista médica, en el juzgado, con la policía, en el ejército, etc...), con prominentes movimientos de cabeza de aceptación y de afirmación fática. Por eso Manel no ponía pegas a la hora de comerse ese mismo plato de botifarra amb seques.

Es decir, que la percepción selectiva determina que el migrado mantenga unas características que lo configuren eficazmente en el papel social que se le ha atribuido. Si es el de un obrero silente, no deberá hablar mucho, pero si -por el contrario- se convierte en jefe, deberá espabilar para interaccionar con autóctonos y con extranjeros. Esa amplia-

\footnotetext{
${ }^{8}$ En Hernández y Villalba (2005) resulta interesante el esfuerzo por adaptar la enseñanza de ELE a los fines laborales (Español con fines laborales: EFL).

9 Cfr. Schmidt (1983) para una propuesta relativa a los factores individuales, sociales y culturales más influyentes a la hora de aprender-adquirir una L2.
} 
ción de recursos no se desarrolla monofuncionalmente. Es muy interesante este pasaje (EUP, I29):

"Ésa fue su mejor época: estaba ganando mucho dinero y había hecho amistad con algún cristiano que no le resultaba del todo desagradable".

El-Hachmi retrata muy bien la tolerancia: se acepta no lo ideal, sino lo conveniente. Ese comentario sobre la amistad con un cristiano que no le resultaba del todo desagradable contrasta perfectamente con esa especie de solidaridad por decreto que parece actuar cuando en un ámbito externo a la propia comunidad los connacionales presuponen un mandato innegociable de autoayuda (Fuori, tutti fratelli, dicen los italianos en el exterior, terroni incluidos), como así se lee en EUP (I33):

Malparido, yo pensaba que eras un maldito cristiano: ¿por qué no me has hablado antes?, a mí sí que se me nota que soy moro. Y tan moro debió decir el otro mientras se daban un apretón de manos.

La percepción es dinámica y se autoconstruye: un moro no viene desde la nada; un moro no es un moro siempre total, desde un punto de vista perceptivo, ya que Jaime le dice a Manel que al no hablarle no podía saber que los dos eran moros.

Como era de esperar, uno de los personajes cuyos rasgos se apuntan con cierta frecuencia en la novela es Mimoun-Manel. Sus vocales interlengüísticas constituyen la consabida igualación vocálica $\mathrm{o}<>\mathrm{u}$ o $\mathrm{e}<>$ i que frecuentemente presentan hablantes de árabe Li o influenciados por el árabe a la hora de hablar español. Todo ello tiene su reflejo en el lecto del patriarca:

La confusión en el uso de las vocales la enfriaba por momentos, ¿ti guchta?, decía él, y ella debía de pensar que si se callara todo iría mejor, pero no dijo nada hasta que se sintió mojada por dentro y tuvo la certeza de que ese hombre le traería un montón de problemas que todavía no había tenido (EUP, I48-I49).

En el original catalán es muy parecido, pues marca de igual manera la conversión e > i (LUP, cat. I44-I45): “...ti guxta? En las páginas 51 y 53 la conocida crema Nivea es nivia; en las páginas 8I y I28 Barcelona es Barciluna. En las vocales velares también aparece la igualación en forma de o > u, como en "viste que él decía uxtia puta" (EUP, 287), en catalán $\left(L U P, 2_{2}\right)$ “...ell havia dit «úxtia puta»...”, expresión que más allá de la marca interlingüística de Manel, representa algo más:

Aún reías cuando padre, pam, cerró la puerta del coche azul que no hacía mucho que se había comprado [...] Querías llorar, pero ya era demasiado mayor para hacerlo. Dijiste ¡aaay!, pero en el momento en que viste que él decía uxtia puta y apretaba la mandíbula moviendo los músculos de aquella forma supiste que no se callaría en todo el trayecto [...] Porque en cuanto dijo uxtia puta entendiste que tenía un episodio de esos suyos, de los que le provocaba esa especie de maldición o enfermedad, o la indignación o el deshonor o vete tú a saber qué o todo eso junto.

Y no paraba de gritar dentro del coche mientras se encogía de vez en cuando sobre el volante. 
Tfu, apestosa cristiana de mierda, tfu. ¿Con qué clase de putas te juntas, tú? ¿es que no sabes que ésa es una puta? (EUP, 287)

¿A qué obedece esta señalización lingüística? ¿Por qué se rompe la ilusión normativista mediante la que se redactan las novelas? Posiblemente es fruto de una percepción donde el centro hegemónico es catalán, o hispánico, ampliamente considerado. Por ello se acogen instintivamente los rasgos más llamativos para un oído nativo catalán, o hispanohablante, de modo que emerge un rasgo diferenciador, dando curso a una sintomatología lingüística que desde luego se presenta en muchísimos otros hispanohablantes marroquíes ${ }^{\mathrm{IO}}$. Funcionaría como un marcador sociolingüístico, que vale tanto para grupos xenolingüísticos como para otros de tipo endolingüístico, como en Brigada Central (Juan Madrid (I989/20Io); Barcelona: Ediciones B), al aparecer un buen número de rasgos fónicos gitanos, especialmente entre las páginas $9^{8}$ y гог, o la mención del acento de muchos personajes en Inés y la alegría (Almudena Grandes, 20ıо; Barcelona: Tusquets). Como recurso literario, parece fuera de toda duda que su utilidad está en fortalecer la verosimilitud del relato, aunque cabría preguntarse si esa señal grupal no fortalece asimismo un repertorio de estereotipos negativos.

En el caso de los hablantes extranjeros, esas marcas grupales también pueden responder a casos de fosilización o de falsa fosilización, ya que desde el punto de vista del análisis de errores la fosilización es el fenómeno lingüístico mediante el cual el aprendiente mantiene en su interlengua, de manera automática y permanente, rasgos ajenos a la lengua meta relacionados con la gramática, la pronunciación, el léxico, el discurso u otros aspectos comunicativos (Vázquez, r99I).

Esta posible señalización lingüística de la foraneidad o extranjería tiene ciertas contrapartidas. En relación con los nombres destaca su poder identitario, al focalizar perfiles concretos de las personas nombradas ${ }^{\text {II }}$. En el siguiente fragmento de EUP (86-87) hay un interesante viraje nominal que -con sus matices- suele reiterarse en situaciones de contacto cultural, donde la parte hegemónica rebautiza, con unas u otras intenciones, a personas de un grupo cultural recién llegado:

El tío habló un rato con él y finalmente el jefe lo repasó de arriba abajo [...] Por cierto, le había dicho su tío, como le cuesta mucho decir tu nombre, dice que a partir de ahora te llamarás Manel.

La situación presenta muchas interpretaciones. Por ejemplo, puede destacarse la soberbia por convertir la ignorancia, incapacidad o el mismo gusto del empresario en un

\footnotetext{
Io En un futuro podría indagarse en el grado de penetración sociolingüística del fenómeno. Recientemente una doctoranda marroquí me comentaba que "Aunque ahora estoy en paro, por lo menos tengo más tiempo para correger la tesis. "Incluso las intensas revisiones siempre dejan algủn gazapo como apareción en tesis que por lo demás son magníficas.

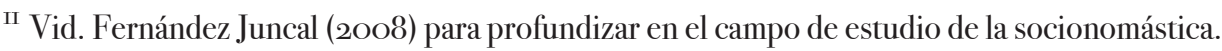


criterio que le lleva a ponerle un nuevo nombre al trabajador. Por el contrario, otro matiz, en un plano probablemente más secundario, es el prurito por acercar, por acortar distancias. Manel es un nombre más común, serás uno de los nuestros, aparte de la jocosidad con que el nombre Mimoun puede ser tomado en una comunidad hispanohablante. En cualquier caso, el nuevo Manel no recibe con desagrado su nuevo nombre.

Operaciones de transformación nominal como la anterior suelen ser bastante frecuentes. En algunos pueblos castellanos se han recibido muchísimas solicitudes de familias musulmanas para cristianizar el nombre de los hijos (de Yussef a José, por ejemplo), mientras que hace bien poco la ley española restringía sobremanera el repertorio de nombres. Es decir, que lo que en un momento histórico dado constituye una coacción, en otro bien puede resultar una elección. El fenómeno alcanza dimensiones masivas en contextos de gran confluencia de extranjeros estudiantes de ELE, donde inmediatamente una Hannah alemana pasará a ser Ana o un Giussepe italiano será llamado Pepe. Cuando se trata de imposiciones más o menos aceptadas, parece que a partir de la percepción selectiva de la extranjería se asimila el nombre, se hace despararecer esa distancia idiomática, acercándola mediante un nuevo nombre semejante a los que ya hay en la comunidad de destino.

Otro fragmento de EUP permite más perspectivas, ya que Manel no es el único caso de acercamiento nominal o, si se quiere también, de uniformización etnolingüística, en este caso con doble filtro, pues "El chico se llamaba Hamed, pero todos lo conocían como Jaume, que venía de Jaime, y entretuvo a Mimoun con todo un repertorio de chistes de zorros y leones”. (EUP, I33).

Ambos tienen cristianizado el nombre, quizá como una estrategia de acercamiento y de uniformización, porque tienen muchos más signos de representación del Otro marroquí.

\section{4- La permanente inversión comunicativa de la niña sin nombre}

Mimoun-Manel quería imponer su jerarquía a toda costa, mientras su mujer se refugiaba como podía. A diferencia del padre, la niña recibe la nueva lengua mediante el aprendizaje, sin que obviamente deje de afectarle la adquisición ${ }^{13}$, mucho más vivencial. Poco a poco su repertorio funcional en la nueva lengua se agrandará considerablemente

\footnotetext{
${ }^{12}$ En la versión catalana se lee “...Hamed, però tots el coneixien per Jaume, que primervenia de Jaime, LUP, cat. 129).

I3 Entiendo que el par conceptual aprendizaje - adquisición, característico de buena parte de la teoría lingüística adquisicional es complementario y gradativo, más que opositivo, no tanto por su naturaleza en sí, sino sobre todo por la eficacia que su eclecticismo suele otorgar a quienes mezclan inteligentemente las dos maneras de conseguir un determinado nivel de dominio lingüístico.
} 
y desde esa ampliación podrá situarse mejor en la nueva comunidad; estudiará, hará de intérprete familiar en situaciones delicadas y podrá emanciparse, desoyendo a su padre, que la habría lanzado a otro patriarca, educada como una buena hija obediente para llegar a ser una buena esposa obediente.

Quizá por ello opera el denominado iceberg perceptivo, pues las sociedades receptoras de migraciones no suelen ser demasiado conscientes de la dificultad que para personas migrantes con otra Li supone el dominio siquiera rudimentario de la nueva lengua. Esos procesos de incorporación a una nueva sociedad, en que la lengua suele tener un papel no poco importante, suelen denominarse de muchas maneras, con importantes matices, sea mantenimiento lingüístico, deslealtad lingüística, fenómenos de auto-odio lingüístico, sea aculturación, adaptación, asimilación, integración, acomodo, anomia, etc (Malgesini y Giménez, 200o; Richards, Platt y Platt 1992/I997). Desde el punto de vista sociolingüístico, la bibligrafía ha hecho hincapié, según la ideología de quienes firmen los trabajos, de una integración unidireccional, por un lado, modelo propio de la ideología monolingüe (Moreno Fernández, 2009) y, por otro, de una ideología plurilingüe o de la linguodiversidad, que considera el proceso desde un punto de vista multidimensional que enriquecería a cada una de las partes ${ }^{\mathrm{I} 4}$.

En EUP, I92, se destapa esa dificultad invisible mediante el abandono activo de la lengua de origen:

Y padre quería que hablásemos en aquella lengua delante de ellos para no ofenderlos, para que no pensaran que decíamos vete tú a saber qué. Pero yo no podía, no podía hablar con él en ninguna otra lengua que no fuese la lengua con la que lo conocí. Me jugaba un guantazo, pero no podía. Podía acostumbrarme a que Mimoun fuese ManeI y a que nosotros ya fuésemos de aquí, pero no podía cambiar al padre Mimoun por el padre Manel.

Esa violencia de la ocultación lingüístico-simbólica se sustenta en una dialéctica colectiva y familiar. El padre se esfuerza por esconder su origen, que entiende como una exigencia de quienes mandan allí. Ese esfuerzo lo proyecta como una norma que ha de cumplir su hija: no hablar en su lengua delante de aquella gente. Leída la novela, tanto da, pues sobre todo se siente la fuerza patriarcal, caprichosa, efervescente, contumaz, hablar esta lengua o aquella, prohibir llevar el velo (EUP, 23o-233) o no llevarlo. A la niña toda esa disciplina de la ocultación le parece un disparate y se rebela. Esa operación violenta de la invisibilidad lingüística es, desde luego, verosímil, presente en los procesos migratorios en curso en Europa y, todo hay que decirlo, también como operación que históricamente ha determinado el desprecio de variedades geográficas en beneficio de normas nacionales. El sintagma aquella lengua parece recuperar una denominación cuasi medieval del magma sociolingüístico de la fragmengtación del latín. Aquella lengua simplemente perfila la reciedumbre inmatizada de la alteridad. Seguramente se refería

\footnotetext{
I4 Para una panorámica sobre el plurilingüismo, cfr. De Mauro (I977); Llorente Pinto (2002); Moreno Cabrera (2006); Martín y Mijares (2007); González, Guillén y Vez (2OIO).
} 
al catalán, pero al obviar la concreción glotonímica viene a decir que resulta indiferente, simplemente la obligaba a hablarle en otra lengua, que no era la lengua en que lo conoció, algo así como el punto preciso en que sabes que tienes padre. Tampoco tiene nombre esa lengua, la lengua propia, aunque indudablemente se refiere al rifeño.

Pero también en Europa hay familias emigradas que lo saben perfectamente: si algo no lo usas, lo pierdes. En este punto es fundamental invertir en ese recurso lingüístico, y la mejor inversión es el uso de la lengua. Solé i Camardons (2OOI: ı28-ı29) lo ha detectado muy bien cuando algunas familias catalanohablantes de las provincias de Valencia y Alicante prefieren "deixar de parlar el català als seus propris fills".

Desde finales de la Edad Media se maneja una metáfora de fuerte raigambre: la la tierra como nutriente comunicativo. Sin embargo, esa metáfora térrea a veces hace aguas, en beneficio de la metáfora de la lactancia (lengua materna), puesto que todavía parece más propia la lengua de la familia que la lengua de la tierra en donde comes, en donde te has criado y en donde vives. En la novela predomina especialmente esa atracción de la lengua hacia un espacio parcialmente desubicado, inconcreto: la lengua del país (EUP, I36), árabe del sur (EUP, 28), en ese otro idioma (EUP, 97), la lengua más cercana (EUP, I33), lengua de la capital de comarca (EUP, 230), lengua de los musulmanes (EUP, 230), o, genéricamente, las cosas de aquí y de allí (EUP, 33I). Precisamente una cuestión que como lector me ha llamado mucho la atención es la denominación con caracteres intemporales que recibe el catalán en la novela, aparte del interés que merece el capítulo Diccionario de la lengua catalana (EUP, I85-I88), que planea también en capítulos posteriores.

La niña, a partir de sus conocimientos lingüísticos, introducidos en escena poco a poco, distingue y valora variedades de la lengua del país, con muchos más matices (EUP, 293):

Era como si lo conociera desde hacía mucho tiempo. Pase, pase, había dicho, y yo gracias. Hablaba la lengua del país con ese acento tan de payés y me hizo gracia, me fijé en él más de la cuenta. ¿Puedo venir a verte cuando acabes las clases?

"...Con ese acento tan de payés", que -si no llega a continuar con ese "me hizo gracia" - quedaría inevitablemente connotado con cierto desdén, como tantas y tantas variedades consideradas rurales en el contexto iberopeninsular. De hecho emergen ciertos datos que apuntan en esa dirección, pues con mucha frecuencia las actitudes sociolingüísticas de la población extranjera en Andalucía adjudican al español de ese lugar concreto muy poco prestigio idiomático, frente al de Sevilla o al centropeninsular castellanista. Es decir, desde un punto de vista de la sociolingüística perceptiva, a veces la población extranjera recrudece en mayor grado los estereotipos que sufre una comunidad de habla, receptora en estas circunstancias.

En el subconsciente colectivo parece operar la necesidad de que existan sibboleths sociolingüísticos. Cuando la realidad no los confirma, parecen quebrarse esas fortísimas presuposiciones sobre el déficit ajeno y se realza de inmediato: si eres extranjero y hablas bien, se enfatiza, lo que quizá sea la otra moneda del estigma, creando una excepción para averiguar la regla: 
Era divertido ir a todas partes con padre. Cuando no había colegio, visitábamos obras, visitábamos clientes y proveedores y todos decían oh, qué bien hablas con lo poco que hace que estás aquí (EUP, 207)

Ello recuerda, y cómo, esa sociosemántica del prejuicio, que se aplica sibilina y adversativamente en frases como Es andaluz, pero muy trabajador; Aunque es catalán, me ha invitado a comer o Ese gitano, qué buen labrador es. Como se ve, esa presuposición negativa influye también en entornos intraestatales, ya que en otras zonas románicas como Lombardía o Piamonte, del Norte italiano, se destaca de inmediato que un italiano de Calabria, por poner un caso, sepa hablar italiano.

En los procesos de adaptación sociolingüísticos se han destacado frecuentemente la importancia, y el sufrimiento también, de factores que multiplican su dificultad. Por un lado estaría la adquisición-aprendizaje de un nuevo código lingüístico, fundamentalmente oral y, por otro, el aprendizaje de su escritura y la nueva práctica cultural que conlleva desde una posición de origen en que la Li carece de sistema de escritura. En ese devenir sociolingüístico se producen compromisos para que la población migrante pueda sobrellevar mejor la nueva situación. Es muy interesante en este alfabetismo adaptativo el siguiente pasaje (EUP, 23I):

Comencé a leer las etiquetas de los alimentos. Madre, estas galletas llevan cerdo. Y ella, qué dices, hala, si son las que hemos comido toda la vida. Pone grasa animal que, en el mejor de los casos, es grasa de un animal que no ha sido sacrificado como debe ser y en el peor de los casos es grasa de cerdo a secas. Íbamos a comprar queso cortado en lonchas y decíamos: nos limpias la máquina, por favor, que antes has cortado jamón, y yo no me acostumbraba a eso.

Los recuerdos de la niña siguen abundando en ciertas inconveniencias de la escolarización (EUP, 23I):

Los maestros nos hacían cantar villancicos y yo no podía decir que no, que yo no los quiero cantar, como tampoco lo hacían las hijas de los testigos de Jehová, que no. Y me situaba entre los niños y cantaba y no cantaba, disimulando, solo moviendo los labios y por dentro diciendo, perdóname, Dios mío, perdóname, ya sé que Jesús no es hijo tuyo, ya sé que están equivocados y ya sé que es de cristianos cantar estas canciones. Pero no habría lamentado para nada tener regalos para Reyes o celebrar otra Navidad, aunque fuese con cuchillos que vuelan o con bombonas de butano cantando vete.

La frontera como compromiso por la supervivencia actúa otra vez. La considero una excelente oportunidad, nuevamente, de repasar nuestra historia, antes incluso de apresurarnos a levantar acta del conocimiento del Otro que está aquí. Los emigrantes españoles en Alemania sufrían equívocos alimentarios, pasando por ciudadanos muy integrados en la República Federal al comprar comida para perros, no para sus mascotas, sino para ellos mismos, confundidos al no saber nada de alemán. Esa confusión la confir- 
ma el extraordinario documental español El tren de la memoria ${ }^{15}$, cuando en Núremberg compraban latas que tenían dibujitos con trocitos de carne, sin saber que era carne para perros, lo que entre los contertulios del documental se asiente, con el comentario de que no se ha muerto nadie; en la higiene personal se tomaba por champú lo que era detergente para lavadoras, cuando en los momentos iniciales de la emigración las onomatopeyas locales pretendían hacerse interculturales al nombrar al pollo (al. Hänchen) como un kikirikí.

Otro buen hito de la sociolingüística del contacto cultural reside en la normalización de las relaciones vecinales, probablemente mediante el habla de y para extranjeros (EUP, 235) en la nebulosa de aquel idioma:

Todo marchaba bien. [...] Una calle que no tenía salida y por donde sólo pasaban coches de los vecinos, donde dábamos vueltas con las bicicletas y donde madre charlaba con las vecinas como podía en aquel idioma que hacía tanto que oía.

Después de todo, hay necesidad de comunicación, aunque sea en forma de mediaciones interculturales espontáneas. Ya se ha hablado de Hamed, conocido en Vic como Jaume, que cumple una función de intérprete, de mentor cultural que va limando las aristas que Manel encuentra por doquier $\left(E U P, \mathrm{I}_{3} 6\right)$ :

Jaume no solo le hacía sentirse a gusto en casa como no se había vuelto a sentir desde que se había marchado del pueblo, sino que lo sacaba de muchos líos. Lo había frenado en el mercado cuando Mimoun quiso pegar a un vendedor que se reía de su forma de hablar la lengua del país o de esa costumbre que conservaba de pedir póngame tantas pesetas de patatas o tantas otras de tomates. Mimoun solía ponerse a gritar cuando el dependiente en cuestión empezaba a reírse con un ¿y éste qué dice ahora?, despectivo, y Jaume, que lo veía venir, se lo llevaba del puesto.

La niña tampoco ceja en esa labor mediadora. Por la vergüenza y pudor tan fuertes que le producía, a la hora de traducir, la niña, en un fragmento extraordinariamente ilustrativo $(E U P, 22 \mathrm{O})$,

Procuraba permanecer detrás de la cortina mientras traducía lo que iba diciendo la comadrona.

Había cuestiones que no sabía pasar de un idioma a otro. Continuaba sin entender por qué tantas mujeres de por ahí me explicaban a mí cosas de aquellas. ¿Cuándo fue la última vez que le vino la regla a tu madre? Y yo ya sabía qué era eso de la regla, pero no lo había hablado nunca con ella. ¿Cuándo fue la primera vez que le vino? A los dieciséis años, mejor, así yo estaré tranquila hasta los dieciséis. ¿Cuándo tuvo relaciones sexuales por primera vez? Dios, Dios, quería huir corriendo de todo aquello, yo no quiero saber todas esas cosas, y aún menos traducirlas a un idioma en el que no existía ninguna palabra que yo conociera para relaciones sexuales que no fuesen palabrotas. No podía correr y la comadrona me miró fijamente con las uñas rojas sobre la mesa, anda, venga, pregúntaselo. Madre me miraba y decía qué, qué te ha preguntado, y

I5 Dirigido por Ana Pérez y Martas Arribas en 2005, narra las dificultades de la población española que emigró a Alemania durante los años 6 o y el terrible proceso sufrido, tanto en su estancia allí como durante su retorno a España. 
yo habría querido fundirme, así, de golpe, y que ellas mismas se las entendieran. No podía decir follar, no. No podía decir cuándo fue la primera vez que padre te la metió. ¿Joder? No. Intenté encontrar un eufemismo. ¿Cuántos años tenías cuando dormiste con padre por primera vez. Y no la miré a los ojos mientras se lo decía; ella dijo, también muy deprisa, nos casamos cuando yo tenía dieciocho años. Eso es todo.

Me acostumbré a leer los trípticos informativos de la sala de espera, unos análisis, unas pruebas, toma hierro, prepara la ropita, etc. Yo tenía ganas de decirle a aquella señora de cabellos muy negros teñidos que madre ya había sido madre tres veces seguidas y que nunca le había pasado nada, sin test de O’Sullivan ni gimnasia preparto.

La traducción, la traducción impensable, puede ser una violación en toda regla a unos principios vitales. La asimetría en el manejo de los dos códigos lingüísticos genera una desigualdad en el uso prototípico de la ampliación léxica y discursiva que procura remediar tabuizaciones sexuales, extendidas a otro ámbito de prohibiciones como los precios y las características de la ropa $\left(E U P, 25^{2}\right)$ :

Al llegar teníamos que ser unos reyes magos, y yo pensé que estaba bien, después de tanto tiempo. Y habíamos tenido que comprar ropa [...] Padre nos llevó a una tienda donde yo no me atrevía ni a traducirle los precios a madre, pero donde la ropa era bonita. Escogí faldas fluorescentes y pantalones por encima de las rodillas.

Queda claro que la niña es ya una niña de aquí que domina varios idiomas, capaz de reflexionar agudamente sobre equivalencias semánticas en su mediación-traducción, frente a su padre Mimoun-Manel, que no tiene más herramientas que la violencia física y, sobre todo, a Hamed-Jaume, que lo calma y le evita males mayores.

\section{6 - Síntesis de la lectura}

En EUP se aprecia que el proceso de adaptación sociolingüística es un itinerario que arranca desde ese iceberg perceptivo en que parte migrante y parte hegemónica van descubriendo elementos mediante un deshielo que descubre caracteres menos evidentes en los comienzos, acercando lo exótico y tomando distancia de lo más conocido. Dentro de esa dinámica, el padre Mimoun-Manel se adapta por la fuerza de las circunstancias, frente a su hija que se hibrida por la fuerza de su voluntad y de su desobediencia. El resto de la familia tiende a ser invisible en la novela; solo la madre lanza a escena otro estereotipo: depositaria de las raíces rifeñas, mantiene a lo largo del tiempo una mera neolengua de supervivencia que le sirve para charlar como buenamente puede con las vecinas, apoyándose para interacciones más complejas en su hija, en la que recaen ingentes responsabilidades sociolingüísticas. Entre otras convicciones, la niña descubre que las diferencias grupales, cuando son vividas, sufridas y también racionalizadas, son menos abismales de lo que parecen a primera vista. Esa hibridación derrota al patriarcado, rifeño en este caso, 
porque no pretende conservar la pureza de la raigambre, no la toma como una esencia, sino como una metamorfosis sin destino, eminentemente como una aventura dolorosa, interactiva y crítica.

Es posible que ese triunfo del mestizaje tenga varias caras, la de quienes lo vivan como una traición o como una excepción, pero, desde luego, la de quienes contrariamente apuesten por la imaginación social y por la capacidad de crear otras categorías que articulen reafirmaciones matizadas de la diferencia con una igualdad conquistada. Muchas propuestas para la visibilización de las culturas emigradas son pertinaces en la detección de categorías esencialistas, para diseñar su contrapunto: empoderar a las comunidades migrantes, enfatizar sus logros y normalizar sus triunfos. EUP, antes que una divulgación del estereotipo folclórico (Zovko, 2OIO), más bien persiste en una ancestral angustia ante la mezcla, casi como una carrera de obstáculos para la transferencia cultural, que necesita relatos como el de estas novelas para derrotar el miedo a unas relaciones colectivas que configuran al moro como un desheredado y a la mora de aquí, ya catalana, como una heroína de frontera.

La novela contiene al mismo tiempo una reacción al patriarcado y muchas proposiciones, pero sobre todo podemos entender que invertir en comunicación, imprescindible, aunque no suficiente, produce sensación de plenitud y de progreso sociocultural y económico. La paciencia para conocer al Otro es simultáneamente el aguante para conocernos a nosotros mismos. Justamente esa podría ser una estupenda premisa en la renovación de nuestra educación literaria y lingüística a partir de novelas como El último patriarca, una extraordinaria novela de legitimación de la alteridad en el Nosotros mismos. 


\section{Referencias}

- Ballester, J. y N. Ibarra (2009). La enseñanza de la literatura y el pluralismo metodológico, en OCNOS, 5, pp. 25-36.

- Baralo, M. y S. Estaire (2OII). Variables socioculturales y comunicativas en el diseño curricular de una certificación de español para trabajadores inmigrantes, en Lengua y Migración, 3:2, 5-4I.

- Bueno Alonso, J. (2OIO). Género, exilio y desterritorialidad en L’últim patriarca de Najat El Hachmi, en L. W. Miampika y P. Arroyo, coords. (20Io). De Guinea Ecuatorial a las literaturas hispanoafricanas. Editorial Verbum, pp. 213-226.

- De Mauro, T. (1977). Il plurilinguismo nella società e nella scuola italiana, en Simone, R. y Ruggiero, G., eds. (1977). Aspetti sociolinguistici dell'Italia contemporanea. Roma: Bulzoni, 87-IO2.

-Eguren Rodríguez, J. (2003). La comunidad transnacional rifeña: un espacio simbólico y real entre España y Marruecos. Obtenido el 20 de mayo de $20{ }^{2}$ desde http://meme.phpwebhosting. $\mathrm{com} /{ }^{\sim}$ migracion/ponencias/ı3_I.pdf

- Fernández Juncal, M. del C. (2008). Patrones sociolingüísticos de la onomástica, en Revista española de lingüística, Año no 38, Fasc. 2, 2008, págs. 5-20.

- Fuentes González, A. D. (2005). Las lenguas como instrumentos de integración, en L. C. Nieto García, dir. (2005). Derechos Humanos e Inmigración. Una Aproximación al Tratamiento Jurídico, Social y Laboral de los Extranjeros. Motril: Ayto. de Motril, págs. 77-IoO.

- Fuentes González (2005a). La Lingüística ante el reto de la inmigración, en M. Casas Gómez y G. Fernández Smith, eds. (2005) IX Jornadas de Lingüística. Cádiz: Universidad de Cádiz, págs. IOI-I38.

- Fuentes González, A. D. (20I3). El nombre de los Otros: Sociolingüística gentilicia en El último patriarca, de Najat El-Hachmi, en Tonos Digital 25 [http://www.tonosdigital.es/ojs/index. $\mathrm{php} /$ tonos/index]

- Fowler, R. (I988). La literatura como discurso social. La práctica de la crítica lingüística. Alicante: Marfil. Trad. de M. F. Rodríguez Álvarez.

- García Marcos, F. J. (i999). Fundamentos críticos de sociolingúística. Almería: Universidad.

- González Piñeiro, M., C. Guillén Díaz y J. M. Vez Jeremías (20IO). Didáctica de las lenguas modernas. Competencia plurilingüe e intercultural. Madrid: Síntesis.

- Grimson, A. (2008). Diversidad y cultura. Reificación y situacionalidad, en Tabula Rasa. Bogotá-Colombia, 8, 45-67, enero-junio 2008. 
- Gutiérrez, R. (2007). Lengua, migraciones y mercado de trabajo, en Biblioteca Universal Complutense. Obtenido el I8 de mayo de 20 I2 desde http://eprints.ucm.es/9687/I/DTo5-Oz.pdf

- Hernández García, M. y F. Villalba Martínez (2005). La enseñanza de español con fines laborales para inmigrantes, en Glosas Didácticas, Revista Electrónica Internacional, nº I5, Otoño de 2005, 74-83.

- Lambert, J. (I999). Literatura, traducción y (des)colonización, en M. Iglesias Santos, ed. (I999). Teoría de los Polisistemas. Estudio introductorio, compilación de textos y bibliografía. Madrid: Arco/Libros S.L., pp. 257-280.

- Lambert, J., Meylaerts, R. y Borden, M. (2005). Lalengua de la literatura: la institucionalización por la mediación del discurso, en Tonos Digital, 9. Obtenido el I9 de mayo de 2012 desde http:// www.um.es/tonosdigital/znumg/estudios/lengualiteratura.htm

- Llorente Pinto, V., coord. (2002). La intercomprensión: Un nuevo enfoque en la enseñanza de las Lenguas. Salamanca: Junta de Castillay León.

- Löffler, H. (1985). Germanistische Soziolinguistik. Berlin: Erich Schmidt.

- Malgesini, G. y C. Giménez (2000). Guía de conceptos sobre migraciones, racismo e interculturalidad. Barcelona: Los Libros de la Catarata.

- Martín Leralta, S. (2OII). Certificación lingüística de nivel inicial para inmigrantes en contexto laboral: ejemplo de una prueba del examen DILE, en Lengua y Migración, 3:I, 89-IO4.

- Martín Rojo, L. y L. Mijares, eds. (2007). Voces del aula. Etnografía de la escuela multilingüe. Madrid: Ministerio de Educación y Ciencia.

- Martos, E. y Campos, M. (2OI2). La lectura y la escritura en el s.XXI: Cultura letrada y modernidad. Álabe 5, www.revistaalabe.com

- Morelló, E. (2002). Actituds de la població migrant davant l'ús del valencià: una altra perspectiva al voltant de la situació social del valencià, en Treballs de sociolingüística catalana, 2002, I6, pp. 24I-254.

- Moreno Cabrera, J. C. (2006). De Babel a Pentecostés. Manifiesto Plurilingüista. Barcelona: Horsori.

- Moreno Fernández, F. (2009). Integración sociolingüística en contextos de inmigración: marco epistemológico para su estudio en España, en Lengua y migración, I, pp. 75-ז2O. 
- Olivieri, M. (I999). Migraciones, estereotipos y prejuicios ayer y hoy: el caso italiano, en Migraciones, I6I-I84.

- Querol Sanz, J. M. (20ıо). El otro magrebí en la la literatura española, en M. Iglesias Santos, coord. (20IO). Imágenes del otro: identidad e inmigración en la literatura y el cine. Biblioteca Nueva., pp. $63^{-86 .}$

- Ricci, C. H. (2OIO). L’ultim patriarca de Najat El Hachmi y el forjamiento de una identidad amazigh-catalana, en Journal of Spanish Cultural Studies. Obtenido el Io de mayo de 2012 desde http://www.tandfonline.com/loi/cjsc2o

- Richards, J. C., J. Platt y H. Platt (1992/I997). Diccionario de lingüística aplicada y enseñanza de lenguas. Barcelona: Ariel. Vers. esp. de C. Muñoz Lahoz y C. Pérez Vidal.

- Schmidt, R. (1983). Interaction, acculturation and acquisition of communicative competence, en N. Wolfson y E. Judd, eds. (1983). Sociolinguistics and second language acquisition. Rowley, Mass.: Newbury House, pp. I37-I74.

- Solé I Camardons, J. (200I). El políedre sociolinguistic. Una iniciació a la sociolingüistica del conflicte. València: Climent Editor.

- Thon, S. (1998). El texto narrativo como discurso social: una perspectiva histórica, en Odber De Baubeta, P. A. (1998). Actas del XII Congreso de la Asociación Internacional de Hispanistas 2I-26 de agosto de 1995, Birmingham, Vol. 7, I998 (Estudios hispanoamericanos II), pp. 287-292.

-Vázquez, G. (199I). Análisis de errores y aprendizaje de español / lengua extranjera. Frankfurt am Main: Peter Lang Verlag.

-Zovko, M. (2OIO). El exotismo, las tradiciones y el folclore en la literatura de inmigración en España, en RiMe (Rivista dell'Istituto di Storia dell'Europa Mediterranea, 5, dicembre 2OIO, pp. 5-22. Obtenido el I4 de mayo de $2 \mathrm{OI}_{2}$ desde http://rime.to.cnr.it/2OI2/RIVISTA/ $\mathrm{N}_{5} / 2 \mathrm{OIO} /$ articoli/Zovko.pdf 